\title{
Resposta do capim Tanzânia a aplicação do nitrogênio e de lâminas de irrigação. I: Produção de forragem
}

\author{
Luís G. T. Soria ${ }^{1}$, Rubens D. Coelho ${ }^{2}$, Valdo R. Herling ${ }^{3} \&$ Valter Pinheiro ${ }^{4}$ \\ 1 Escola Agrotécnica Federal de Catu/BA. Rua Barão de Camaçari 118, CEP 48110-000, Catu, BA. Fone: (71) 641-1043. \\ E-mail: tsoria@terra.com.br (Foto) \\ ${ }^{2}$ ESALQ/USP. Av. Pádua Dias 11, CEP 13418-900, Piracicaba, SP. Fone: (19) 429-4117. E-mail: rdcoelho@esalq.usp.br \\ ${ }^{3}$ FZEA/USP. CP 23, CEP 13635-900, Pirassununga, SP. Fone: (19) 3565-4114. E-mail: vrherlin@usp.br \\ ${ }^{4}$ ESALQ/USP. E-mail: vpdantas@yahoo.com.br
}

Protocolo 170 - 13/11/2002 - Aprovado em 29/10/2003

Resumo: Com o objetivo de estudar o efeito da lâmina total de água aplicada, da adubação nitrogenada e da interação entre elas sobre os fatores de crescimento, de produção, de eficiência de uso e qualidade da forragem durante um ciclo de crescimento no capim Tanzânia (Panicum maximum cv. Tanzania) e determinar funções de produção para massa seca total, foliar e de haste buscando-se encontrar o nível máximo de produção e econômico de cada fator de produção analisado, montou-se um experimento com delineamento estatístico de parcela sub-subdividida, em cuja parcelas foram distribuídas as diferentes lâminas de irrigação $(0,30,70,100$ e 150\% de capacidade de campo (CC)), nas subparcelas as doses de nitrogênio (0, 100, 275, 756 e 2079 $\mathrm{kg} \mathrm{N} \mathrm{ha}^{-1} \mathrm{ano}^{-1} \mathrm{e}$, nas sub-subparcelas, as coletas analisadas dentro de cada período climático amostrado (verão, inverno e primavera). As maiores lâminas de irrigação proporcionaram efeitos negativos sobre a produção de massa seca. $O$ uso de doses de nitrogênio superiores a $756 \mathrm{~kg}$ $\mathrm{N}$ ha ${ }^{-1}$ ano $^{-1}$ não proporcionou efeito crescente sobre a produção de massa seca, sendo que os percentuais de incremento nas produções pelo uso de nitrogênio até a máxima produção de massa seca total e foliar, mostraram ser de 15, 19, 29 e $20 \%$ (16\% foliar), quando usados as doses de 100, 275, 756 e $1.769 \mathrm{~kg} \mathrm{~N} \mathrm{ha}^{-1}$ ano $^{-1}$, respectivamente.

Palavras-chave: lâmina de irrigação, adubação nitrogenada, Panicum maximum , capim Tanzânia, estacionalidade

\section{Response of Tanzania grass to nitrogen and irrigation depth. I: Production of forage}

Abstract: With the objective to study the effect of total depth of water, nitrogen fertilization and their interaction on the growth factors, production, efficiency of use and forage quality as well as to determine production functions for total, foliar and stem dry matter of Tanzania grass (Panicum maximum cv. Tanzania) with the intention to obtain level of maximum and economic production of each analyzed production factor. The experiment was carried out in split-splitplot, where in the main plots the different irrigation levels were distributed $10,30,70,100$ and $150 \%$ of field capacity (FC)), in the split plot the levels of nitrogen $(0,100,275,756$ and 2079 $\mathrm{kg} \mathrm{N} \mathrm{ha}^{-1}$ year $^{-1}$ ) and in the split-split plot the three climatic periods (summer, winter and spring). The higher irrigation regimes provided negative effects on the production of dry matter. The use of nitrogen levels above $756 \mathrm{~kg} \mathrm{~N} \mathrm{ha}^{-1}$ year ${ }^{-1}$ did not show effect on the production of dry matter, the increments in the total and foliar production of dry matter for the levels of 100 , 275,756 and $1.769 \mathrm{~kg} \mathrm{~N}^{-1}$ year $^{-1}$ were 15, 19, 29 and $20 \%$ (16\% foliar), respectively.

Key words: irrigation levels, nitrogen fertilization, Panicum maximum, grass Tanzania, seasonal effect 


\section{INTRODUÇÃO}

O capim Panicum maximum Jacq., planta de origem africana, é uma das gramíneas mais difundidas no Brasil.

As pastagens apresentam estacionalidade de crescimento durante o ano; todavia, atingem, em determinados momentos, sua melhor qualidade de pastoreio, em função das condições climatológicas: temperatura, luminosidade e disponibilidade hídrica (Vallentine, 1990).

A escolha de técnicas que equacionem o problema decorrente da estacionalidade de produção das plantas forrageiras deve ser coerente com o nível da exploração pecuária. A técnica de irrigação em pastagens durante o período de estiagem no Brasil Central, associada à adubação nitrogenada em trabalhos experimentais, tem mostrado aumento na produção, entre 20 e $70 \%$ sobre a testemunha, no período de 150 dias (Corsi, 1978).

A resposta à associação da adubação nitrogenada com a irrigação tem sido mostrada tanto no período seco, como no chuvoso, visando suprir veranicos nesse período. Estudando a produção dos capins sempre-verde (Panicum maximum.), gordura (Melinis minutiflora) e pangola (Digitaria decumbens), no município de Viçosa, MG, Ladeira et al. (1966) observaram que o uso simultâneo de adubação nitrogenada e irrigação no período seco, proporcionou uma produção de massa verde até $24 \%$ superior à testemunha. Resultados semelhantes foram obtidos por Ararat \& Tafur (1990). O uso em associação de tais fatores pode proporcionar mudanças nos teores de proteína das forrageiras (Dias et al., 1998).

Apesar da importância da interação nitrogênio-água nos aspectos quantitativos e qualitativos das forragens, poucos estudos foram conduzidos no Brasil, definindo as doses ideais desses fatores. O presente trabalho teve como objetivo básico definir as doses de nitrogênio e água, para otimizar a produção de forragem do capim Tanzânia no Estado de São Paulo.

\section{MATERIAL E MÉTODOS}

O experimento foi conduzido em área localizada na Fazenda Areão, pertencente a Escola Superior de Agricultura "Luiz de Queiroz", em um solo Argissolo eutrófico, A moderado textura argilosa, com um incremento de argila no horizonte B e declividade média de $4 \%$, pelo período de 1 ano, no qual foram efetuados 9 cortes da forragem, sendo a gramínea utilizada o Capim Tanzânia (Panicum maximum Jacq. cv. Tanzânia).

A área foi preparada mecanicamente em fevereiro de $2000 \mathrm{e}$ semeada no início de março, com posterior vedação por 6 meses para possibilitar a formação da pastagem.

A adubação nitrogenada para a formação da forrageira foi feita em cobertura, 30 dias após a germinação, com $40 \mathrm{~kg} \mathrm{~N} \mathrm{ha}^{-1}$ na forma de uréia e após três meses, no momento do primeiro pastejo, utilizando-se a dose de $20 \mathrm{~kg} \mathrm{~N} \mathrm{ha}^{-1}$ na forma de uréia, todas via fertirrigação por pivô central.

O experimento foi conduzido durante 1 ano, sendo que, após cada época de corte da forragem, feita a $20 \mathrm{~cm}$ de altura da superfície do solo e levando em consideração os diferentes períodos de crescimento da forrageira, fez-se uma análise de variância dentro de um modelo de parcela sub-subdividida, sendo as coletas analisadas dentro de cada período climático amostrado (verão, inverno e primavera).

As datas de coletas experimentais dentro de cada período climático, foram:
- Verão:
$1-21 / 11 / 2000$ a $26 / 12 / 2000$
$2-02 / 01 / 2001$ a $06 / 02 / 2001$
$3-14 / 02 / 2001$ a $21 / 03 / 2001$
- Inverno:
$4-30 / 03 / 2001$ a $04 / 05 / 2001$
$5-11 / 05 / 2001$ a $15 / 06 / 2001$
$6-20 / 06 / 2001$ a $25 / 07 / 2001$
- Primavera:
$7-27 / 07 / 2001$ a $31 / 08 / 2001$
$8-03 / 09 / 2001$ a $08 / 10 / 2001$
$9-10 / 10 / 2001$ a $14 / 11 / 2001$

Nas parcelas foram distribuídas as diferentes lâminas de irrigação e, nas sub-parcelas as doses de nitrogênio $(0,100$, 275,756 e $2079 \mathrm{~kg} \mathrm{~N} \mathrm{ha}^{-1}$ ano $^{-1}$ ) divididas em nove aplicações). As áreas das parcelas e subparcelas foram de 105 e $15 \mathrm{~m}^{2}$, respectivamente.

O monitoramento do potencial de água no solo foi realizado através de tensiômetro digital, em que as lâminas de irrigação nas parcelas se constituíam de uma fração da parcela de referência mantida na capacidade de campo (padrão) (100\% $\mathrm{CC}$ ). As lâminas de água aplicadas nessas parcelas foram de 0 , 30 e $70 \%$ da lâmina de água a ser reposta no padrão $(100 \%$ CC) e 50\% a mais da lâmina necessária ao padrão (150\%), totalizando 5 lâminas de irrigação no experimento. $O$ controle da umidade na parcela padrão foi efetuado através de 4 baterias de 6 tensiômetros a 10, 20, 40, 60, 80 e $100 \mathrm{~cm}$ de profundidade, com leitura diária, sempre no mesmo horário.

O corte da forragem ocorreu através de uma roçadeira motorizada, a intervalos de 36 dias, sendo que, após o corte, as subparcelas recebiam as adubações com nitrogênio nas doses predeterminadas, via fertigação com nitrato de amônio, sendo as doses anuais divididas em função do número de cortes. Nos dois primeiros períodos de coleta, em função da indisponibilidade de nitrato de amônio, as subparcelas receberam adubação com uréia, onde considerou-se uma perda estimada de $20 \%$ do produto, por volatilização.

A freqüência de irrigação e a quantidade de água aplicada foram determinadas em função da variação do potencial mátrico acusado pelos tensiômetros. As curvas de retenção de água do solo foram obtidas em laboratório, com amostras de solos indeformadas, utilizando-se mesa de retenção e placa porosa, coletadas em três profundidades $(0-20 ; 20-40$ e 40-60 cm). Através do potencial mátrico $\left(\psi_{\mathrm{s}}\right)$ dado pelo tensiômetro e da equação de van Genuchthen (1980), determinou-se a umidade no solo:

$$
\theta=\theta_{\mathrm{pmp}}+\frac{\theta_{\mathrm{s}}-\theta_{\mathrm{pmp}}}{\left[1+\left(\alpha * \mid \Psi_{\mathrm{s}}\right)^{\mathrm{n}}\right]^{\mathrm{m}}}
$$

onde:

$\theta_{\mathrm{s}} \quad$ - conteúdo de água volumétrico $\left(\mathrm{cm}^{3} \mathrm{~cm}^{-3}\right)$ no solo 
$\theta_{\mathrm{s}} \quad$ - conteúdo de água volumétrico $\left(\mathrm{cm}^{3} \mathrm{~cm}^{-3}\right)$ no solo saturado

$\theta_{\mathrm{pmp}}$ - conteúdo de água volumétrico $\left(\mathrm{cm}^{3} \mathrm{~cm}^{-3}\right)$ no solo no ponto de murcha permanente

$\psi_{\mathrm{s}} \quad$ - potencial matricial de água no solo $(\mathrm{cm} \mathrm{c} \mathrm{a})$

$\alpha \quad$ - fator escalar para o $\psi_{\mathrm{s}}\left(1 \mathrm{~cm}^{-1}\right)$;

m e n- parâmetros da curva de inclinação

A irrigação iniciou-se quando a média dos tensiômetros posicionados a $20 \mathrm{~cm}$ de profundidade registrou $-20 \mathrm{kPa}$, sendo que, para repor a água perdida nas parcelas experimentais, utilizou-se a irrigação por gotejamento, com emissores autocompensantes distanciados $50 \mathrm{~cm}$ na linha irrigada e $70 \mathrm{~cm}$ entre linhas, distribuídos sobre a superfície do solo. A vazão nominal do gotejador (RAM - autocompensado) era de $1,6 \mathrm{~L} \mathrm{~h}^{-1} \mathrm{e}$ as linhas posicionadas dentro das subparcelas.

A coleta das subparcelas, que representam uma área útil de $2 \mathrm{~m}^{2}$, foi feita, a $20 \mathrm{~cm}$ do solo, conforme a recomendação de Garcia (1993) sendo que, após o corte, a forragem foi pesada no campo, com o objetivo de se determinar a massa verde ou fresca. Desse material fresco e previamente muito bem uniformizado, retiraram-se as amostras representativas de cada subparcela (aproximadamente $1 \mathrm{~kg}$ de material verde) que foram identificadas e colocadas em saco de papel, para procedimento de pré-secagem, em estufa com circulação forçada de ar a 65 ${ }^{\circ} \mathrm{C}$, por $72 \mathrm{~h}$, até peso seco constante. Os materiais pesados em balança semi-analítica foram moídos em moinho tipo Wiley, passados em peneira de $1 \mathrm{~mm}$ de diâmetro e acondicionados em recipientes de vidro. A secagem definitiva foi obtida tomando-se sub-amostras de $5 \mathrm{~g}$ do material pré-seco e transferindo-as para estufa a $105^{\circ} \mathrm{C}$, por $24 \mathrm{~h}$, procedendo-se à pesagem final após uma hora (Garcia, 1993). A quantidade de massa seca foi determinada através da fórmula:

$$
\text { Prod. }\left(\text { MS kg ha }^{-1}\right)=\frac{\text { Prod. For. Verde } \times \% \text { MS da For. }}{100}
$$

\section{RESULTADOS E DISCUSSÃO}

\section{Avaliação do efeito do uso de adubação nitrogenada}

Dentro da maioria das dosagens de nitrogênio e épocas de coleta, as lâminas de irrigação não mostraram efeitos significativos para as produções de massa seca, mas somente efeito negativo, quando na presença de excesso de água no solo. Os resultados das equações de regressão para variação da dose de adubação nitrogenada dentro de cada lâmina de irrigação e coleta, e dentro de cada coleta em três estações climáticas, para a massa seca total (folha + haste) em pastagem de capim Tanzânia encontram-se na Tabela 1.

Já para os dados de produção de massa seca foliar e de haste foi considerada a interação dupla entre tempo de coleta e dose de nitrogênio, visto que, com o aumento da quantidade de dados amostrais, obteve-se diminuição na variância dos valores de produção encontrados e, assim, a possibilidade de se encontrar, na análise de variância, efeitos significativos dentro desta interação dupla nas três estações climáticas estudadas, sendo que esta variação foi maior durante as
Tabela 1. Equações de regressão para variação de dose de adubação nitrogenada dentro de cada lâmina de irrigação e coleta, na estação do verão (A), inverno (B) e primavera (C) para a massa seca total em pastagem de capim Tanzânia estabelecido num Argissolo, em área experimental da Fazenda Areão, Piracicaba, SP

\begin{tabular}{|c|c|c|c|c|c|}
\hline Lâmina $^{1}$ & Coleta & Equação & $\mathrm{R}^{2}$ & MPMS $^{2}$ & $\begin{array}{c}\text { Dose } \mathrm{N} \\
\text { para } \\
\text { MPMS }^{3}\end{array}$ \\
\hline \multicolumn{6}{|l|}{ A. Verão } \\
\hline 0 & \multirow{5}{*}{1} & NS & - & - & - \\
\hline 30 & & $3.273,44+1,09 \mathrm{X}$ & $0,45^{*}$ & $5.539,6$ & $2.079,0$ \\
\hline 70 & & $3.689,75+0,62 X$ & $0,36^{@}$ & $4.978,7$ & $2.079,0$ \\
\hline 100 & & $2.789,79+0,94 X$ & $0,87^{*}$ & $4.744,1$ & $2.079,0$ \\
\hline 150 & & NS & - & - & - \\
\hline 0 & \multirow{5}{*}{2} & $1.579,19+2,32 X$ & $0,93^{* *}$ & $6.402,4$ & $2.079,0$ \\
\hline 30 & & $2.065,42+0,92 X$ & $0,31^{*}$ & $3.978,1$ & $2.079,0$ \\
\hline 70 & & $1.542,44+2,07 \mathrm{X}$ & $0,95^{* *}$ & $5.845,9$ & $2.079,0$ \\
\hline 100 & & $\begin{array}{c}819,8+4,69 X- \\
0,0013 X^{2}\end{array}$ & $0,94^{@}$ & $5.049,8$ & $1.803,8$ \\
\hline 150 & & $1.468,39+1,63 X$ & $0,92^{* *}$ & $4.863,4$ & $2.079,0$ \\
\hline 0 & \multirow{5}{*}{3} & NS & - & - & - \\
\hline 30 & & NS & - & - & - \\
\hline 70 & & $1.312,58+0,81 X$ & $0,76^{*}$ & $2.996,6$ & $2.079,0$ \\
\hline 100 & & $1.547,23+0,65 X$ & $0,52^{@}$ & $2.898,6$ & $2.079,0$ \\
\hline 150 & & $1.022,79+1,08 X$ & $0,83^{\text {** }}$ & $3.268,1$ & $2.079,0$ \\
\hline
\end{tabular}

B. Inverno

0

30 , $19+3,27 \mathrm{X}-$ $0,0011 \mathrm{X}^{2}$

$0,98^{* *}$

$3.204,4$

$1.486,4$

$1.404,74+2,06 \mathrm{X}-$ $0,00079 \mathrm{X}^{2}$

$4 \quad 1.454,09+1,88 \mathrm{X}-$ $0,00049 \mathrm{X}^{2}$

$0,56^{*} \quad 2.747,7$

$1.303,8$

70

$0,86^{*}$

$3.257,4$

$1.918,4$

100

$$
1.547,95+0,75 \mathrm{X}
$$

$0,84^{* *}$

$3.107,2$

$2.079,0$

150

0

30

70

$1.060,52+0,69 \mathrm{X}$

$0,63^{* * * *}$

$2.349,5$

$2.079,0$

$$
\text { NS }
$$

$361,96+1,17 X-$ $0,00047 \mathrm{X}^{2}$ NS

100
150

5

$394,93+$

$373,63+0,34 X$

$0,88^{*}$

$1.090,1$

$1.244,7$

150

0
30

30

70

NS

100
150

6

$392,96+0,26 \mathrm{X}$

$329,46+0,28 \mathrm{X}$

$326,44+0,28 \mathrm{X}$

$0,89^{*}$

$0,97^{* *}$

893,9

$2.079,0$

$706,9 \quad 2.079,0$

C. Primavera

\begin{tabular}{llllll} 
Crimavera & & & & \\
0 & & $473,97+0,34 \mathrm{X}$ & $0,55^{*}$ & $1.180,8$ & $2.079,0$ \\
30 & & $502,32+0,46 \mathrm{X}$ & $0,77^{*}$ & $1.458,7$ & $2.079,0$ \\
70 & 7 & $558,64+0,68 \mathrm{X}$ & $0,85^{* * *}$ & $1.972,4$ & $2.079,0$ \\
100 & & $452,42+0,61 \mathrm{X}$ & $0,86^{* * *}$ & $1.720,6$ & $2.079,0$ \\
150 & & $597,30+0,59 \mathrm{X}$ & $0,68^{* *}$ & $1.823,9$ & $2.079,0$ \\
0 & & $497,58+0,57 \mathrm{X}$ & $0,60^{* * *}$ & $1.682,6$ & $2.079,0$ \\
30 & & $557,09+0,82 \mathrm{X}$ & $0,74^{* * *}$ & $2.261,9$ & $2.079,0$ \\
70 & 8 & $671,28+1,01 \mathrm{X}$ & $0,79^{* * * *}$ & $2.771,1$ & $2.079,0$ \\
100 & & $599,77+0,99 \mathrm{X}$ & $0,76^{* * * *}$ & $2.657,9$ & $2.079,0$ \\
150 & & $526,65+1,19 \mathrm{X}$ & $0,82^{\text {**** }}$ & $3.000,7$ & $2.079,0$ \\
0 & & $1.514,16+1.15 \mathrm{X}$ & $0,49^{\text {**** }}$ & $3.905,0$ & $2.079,0$ \\
30 & & $1.207,03+1,18 \mathrm{X}$ & $0,79^{\text {****}}$ & $3.660,3$ & $2.079,0$ \\
70 & 9 & $1.245,48+1,24 \mathrm{X}$ & $0,87^{* * *}$ & $3.823,4$ & $2.079,0$ \\
100 & & $1.334,86+1,47 \mathrm{X}$ & $0,82^{* *}$ & $4.390,9$ & $2.079,0$ \\
150 & & $1.132,87+1,54 \mathrm{X}$ & $0,93^{* *}$ & $4.345,5$ & $2.079,0$ \\
\hline
\end{tabular}

${ }^{1}$ Porcentagem da capacidade de campo

${ }^{2}$ MPMS - Máxima produção de massa seca total obtido no experimento $\left(\mathrm{kg} \mathrm{MS} \mathrm{ha}^{-1} 36\right.$ dias $\left.^{-1}\right)$

${ }^{3} \mathrm{~kg} \mathrm{~N} \mathrm{ha}^{-1}$ ano $^{-1}$ aplicado no experimento

$* \mathrm{p}<0,05 ; * * \mathrm{p}<0,01$; NS - Não significante 
estações de inverno e primavera, quando pequenas variações de produção de massa seca nas subparcelas ocasionaram efeitos importantes nos resultados das análises estatísticas efetuadas.

\section{Produção de massa seca total (folha + haste)}

O efeito do uso de dose de nitrogênio dentro de cada lâmina de irrigação e coleta considerada dentro das três estações estudadas, mostrou-se significativo para a produção de massa seca total (Tabela 1A, B e C) sendo que o comporta-mento quanto às equações de regressões encontradas, mostraram-se com maior tendência de efeito linear para produção de massa seca total com a aplicação de nitrogênio, quando consideradas as diferentes lâminas de irrigação usadas.

Vicente-Chandler et al. (1962) visando observar a resposta de Panicum maximum ao uso de diferentes doses de nitrogênio $\left(0,224,448,720\right.$ e $896 \mathrm{~kg} \mathrm{~N} \mathrm{ha}^{-1}$ ano $\left.^{-1}\right)$ em diferentes freqüências de aplicações colhida a cada 45 dias, mostraram que o uso de nitrogênio proporcionou aumento na produção anual de massa seca produzida na ordem de 2,3 (224 $\left.\mathrm{kg} \mathrm{N} \mathrm{ha}^{-1} \mathrm{ano}^{-1}\right), 3,8$ (448 $\mathrm{kg} \mathrm{Nha}^{-1}$ ano $\left.^{-1}\right), 4,7\left(720 \mathrm{~kg} \mathrm{~N} \mathrm{ha}^{-1} \mathrm{ano}^{-1}\right)$ e 5,4 (896 kg N ha ${ }^{-1}$ ano $\left.^{-1}\right)$ vezes, quando comparado com a testemunha. Os valores de coleta médios da produção de massa seca total, obtidos durante as estações de verão, primavera e inverno, foram de 4.816, 3.696 e $2.912 \mathrm{~kg} \mathrm{MS} \mathrm{ha}^{-1}$ quando utilizado uma adubação de 720 $\mathrm{kg} \mathrm{N} \mathrm{ha}^{-1} \mathrm{ano}^{-1}$; assim, as gramíneas tendem a mostrar respostas mais intensivas à fertilização com nitrogênio, durante as estações de maior rapidez de crescimento, que durante os meses de inverno, que são frios e secos (Vicente-Chandler, 1973).

$\mathrm{O}$ uso de nitrogênio permitiu observar uma diferenciação de produção de massa seca total, entre as três estações climáticas estudadas, com variações de produção durante o ano agrícola que seguiram as modificações climáticas (Tabela 1A, B e C), o que mostrou um evidente efeito da ocorrência estacionalidade de produção de biomassa, devido à presença de fatores climáticos limitantes ao crescimento do capim como temperatura e luz, na região de Piracicaba, SP.

Na estação do verão, a produção média de massa seca total das parcelas que não receberam adubo nitrogenado (média das produções iniciais determinadas pelas equações de regressão da Tabela 1), foram maiores durante a primeira coleta experimental (3.250,0 kg MS ha-1), quando comparando às demais coletas (1.494 e $1.293 \mathrm{~kg} \mathrm{MS} \mathrm{ha}^{-1}$ ). Esta maior produção inicial em todas lâminas de irrigação dentro da primeira coleta, pode ter ocorrido por dois fatores: a) aumento das precipitações naturais e da temperatura média diária; b) maior mineralização da massa orgânica recém depositada após o pastoreio, e também daquela massa orgânica incorporada após a implantação da pastagem na área experimental.

Possivelmente, o grande número de animais usados para o pastejo inicial ( 25 animais por $1200 \mathrm{~m}^{2}$ ), tenham deixado um excesso de excreções sobre o solo, de maneira que a mineralização das formas orgânicas hidro-solúveis e do material sólido coloidal possam ter sido rápida, e ter aumentado a concentração de nitrogênio mineral em um curto espaço de tempo (Jarvis et al., 1995). Geralmente a maior parte do nitrogênio incorporado na biomassa microbiana é facilmente biodegradável, liberando nitrogênio inorgânico à taxas dependente somente da razão $\mathrm{C}: \mathrm{N}$, que deve ser menor no esterco recém defecado.
Com uma pequena diminuição da temperatura média, da evapotranspiração e radiação global a partir de março de 2001, ocorreu queda de aproximadamente $40 \%$ na produção total de massa seca total em comparação com os demais períodos nesta estação.

No período denominado inverno, apresentam-se de maneira clara, os efeitos das mudanças provocadas pelo clima, a produção média de massa seca total das parcelas que não receberam adubo nitrogenado (média das produções iniciais determinadas pelas equações de regressão da Tabela 1B), em que, a partir da quarta coleta $\left(1.247,8 \mathrm{~kg} \mathrm{MS} \mathrm{ha}^{-1}\right)$, teve-se uma redução de aproximadamente $69 \%$ na produção de massa seca nas duas coletas subseqüentes (376,0 e 349,0 kg MS ha-1) sendo que as mesmas proporções de redução de produção de massa seca total (69\%) foram encontradas quando se consideram as doses máximas de nitrogênio estimadas.

Aumentos médios crescentes acima de 30\% em média nas produções de massa seca total (efeito linear), quando acompanhados dos aumentos de temperatura diária e evapotranspiração a partir de agosto de 2001 (primavera) foram encontrados com e sem uso de adubação nitrogenada.

Pinheiro (2002) usando uma metodologia para estimativa da produtividade do capim Tanzânia (Panicum maximun cv. Tanzânia) através de um modelo matemático (função de Gompertz), calibrado em função do somatório de unidades fototérmicas e níveis de adubação nitrogenada 0, 100, 275, 756 e $2.079 \mathrm{~kg}$ de $\mathrm{N} \mathrm{ha}^{-1}$ ano $^{-1}$, conduzido de janeiro a dezembro de 2001, no município de Piracicaba,SP. A produção de massa seca do capim Tanzânia, avaliada na época de corte no período de 2/1/2001 a 21/12/2001, apresentou estacionalidade de produção devido aos fatores de crescimento (radiação solar e temperatura) chegando à máxima produção de 4.570,8 $\mathrm{kg} \mathrm{MS} \mathrm{ha}^{-1}$, no mês de fevereiro, após um período de 36 dias de descanso, com adubação de $2079 \mathrm{~kg} \mathrm{~N} \mathrm{ha}^{-1}$ ano $^{-1}$, e à mínima produção de $292,30 \mathrm{~kg} \mathrm{MS} \mathrm{ha}^{-1}$, no mês de julho, após um período de 36 dias de descanso.

As subparcelas testemunha que receberam dose zero de nitrogênio mostraram, no final do período experimental, uma degradação significativa da parte aérea, o que resultaria a médio prazo em uma possível eliminação total do capim Tanzânia por plantas invasoras nessas parcelas experimentais.

Nascimento Jr. et al.(1994) citaram algumas formas de avaliação do grau de degradação das pastagens, nos quais um método que pareceu ser bastante prático é o que avalia a condição da pastagem dividindo-a em quatro classes de degradação que dependiam da condição de pastagem, presente na área trabalhada (pastagem excelente, boa, razoável e pobre). No final do trabalho experimental, as pastagens degradadas se mostravam classificadas como condição de pastagem pobre, apresentando menos de $25 \%$ da sua produção potencial, no período final experimental.

$\mathrm{O}$ efeito do uso do nitrogênio durante todo o período experimental, proporcionou nas doses máximas de nitrogênio estimadas pelas equações, aumentos de mais de 50\% nas produções de massa seca total em capim Tanzânia, cujas variações mensais a partir da segunda coleta foram de 71,58 , $58,58,62,68,77$ e $68 \%$, respectivamente, quando comparadas às subparcelas não adubadas. Exceção foi encontrada na 
primeira coleta, que devido aos fatores já discutidos, apresentou diferença de somente $36 \%$ entre a mínima e a máxima dosagem usadas de nitrogênio.

\section{Produção de massa seca foliar e de hastes}

Os resultados das equações de regressão para variação de doses de adubação nitrogenada, nas três estações climáticas, para a massa seca foliar e de hastes, em pastagem de capim Tanzânia, encontram-se nas Tabela 2.

Tabela 2. Equações de regressão para variação de dose de nitrogênio dentro de cada coleta, nas três estações climáticas para a massa seca foliar (A) e de haste (B) em pastagem de capim Tanzânia estabelecido num Argissolo, avaliados em área na Fazenda Areão, Piracicaba, SP

\begin{tabular}{|c|c|c|c|c|c|}
\hline Estação & Coleta & Equação & $\mathrm{R}^{2}$ & $\mathrm{MPMS}^{1}$ & $\begin{array}{c}\text { Dose N para } \\
\text { MPMS }^{2}\end{array}$ \\
\hline \multicolumn{6}{|c|}{ A. Massa foliar } \\
\hline \multirow{3}{*}{ Verão } & 1 & $2.852,31+0,51 X$ & $0.85^{* *}$ & $4.931,8$ & $2.079,0$ \\
\hline & 2 & $\begin{array}{c}1.241,9+2,84 \mathrm{X}- \\
0,00073 \mathrm{X}^{2}\end{array}$ & $-0,99^{* *}$ & $4.004,1$ & $1.945,2$ \\
\hline & 3 & $1.388,34+0,33 X$ & $0,71^{*}$ & $2.074,4$ & $2.079,0$ \\
\hline \multirow{3}{*}{ Inverno } & 4 & $\begin{array}{c}659,53+1,05 X- \\
0,00042 X^{2}\end{array}$ & $0,89^{* * * *}$ & $1.315,8$ & $1.250,0$ \\
\hline & 5 & $\begin{array}{c}351,89+0,59 X- \\
0,00022 X^{2}\end{array}$ & $0,65^{*}$ & 747,5 & $1.340,9$ \\
\hline & 6 & $\begin{array}{c}178,64+0,71 X- \\
0,00025 X^{2}\end{array}$ & $0,97^{* *}$ & 682,7 & $1.420,0$ \\
\hline \multirow{3}{*}{ Primavera } & 7 & $\begin{array}{c}187,57+1,46 X+ \\
0,0005 X^{2}\end{array}$ & $0,99^{* *}$ & $1.253,4$ & $1.253,4$ \\
\hline & 8 & $\begin{array}{c}199,29+2,79 X- \\
0,00094 X^{2}\end{array}$ & $0,99^{* *}$ & $2.269,5$ & $1.484,0$ \\
\hline & 9 & $\begin{array}{c}780,75+3,94 X- \\
0,0013 X^{2}\end{array}$ & $0,99^{* *}$ & $3.766,0$ & $1.515,4$ \\
\hline \multicolumn{6}{|c|}{ B. Massa haste } \\
\hline \multirow{3}{*}{ Verão } & 1 & $334,06+0,19 X$ & $0,85^{* *}$ & 729,1 & $2.079,0$ \\
\hline & 2 & $77,54+0,48 X$ & $0.98^{* * * *}$ & $1.075,5$ & $2.079,0$ \\
\hline & 3 & $167,49+0,11 X$ & $0,73^{@}$ & 396,2 & $2.079,0$ \\
\hline \multirow{3}{*}{ Inverno } & 4 & $\begin{array}{c}494,62+1,21 X- \\
0,00029 X^{2}\end{array}$ & $0,96^{* *}$ & $1.758,8$ & $2.086,2$ \\
\hline & 5 & $84,70+0,094 X$ & $0,97^{*}$ & 279,9 & $2.079,0$ \\
\hline & 6 & $124,68+0,06 X$ & NS & 249,4 & $2.079,0$ \\
\hline \multirow{3}{*}{ Primavera } & 7 & $144,13+0,15 X$ & $0,89^{* * * *}$ & 455,9 & $2.079,0$ \\
\hline & 8 & $16,29+0,13 X$ & $0,96^{* *}$ & 286,6 & $2.079,0$ \\
\hline & 9 & $1,69+0,24 X$ & $0,99^{* * *}$ & 500,7 & $2.079,0$ \\
\hline
\end{tabular}

A variação dos valores de produções de massa seca foliar, usando-se as dosagens $0 \mathrm{~kg} \mathrm{~N} \mathrm{ha}^{-1}$ ano $^{-1} \mathrm{e}$ de máxima produções observadas na Tabela $2 \mathrm{~A}$, durante os nove períodos de coletas, mostra a ocorrência da estacionalidade de produção da massa em proporções semelhantes à massa seca total.

As máximas doses de nitrogênio indicadas na Tabela 2A, que proporcionam as maiores produções de massa seca foliar mostraram, a partir do estabelecimento dos ciclos de coleta $\left(4^{\mathrm{a}}\right)$ que menores quantidades de nitrogênio seriam necessárias para obtenção de uma produção máxima de massa seca foliar, que aquelas encontradas na Tabela 1A, B e C, para massa seca total, o que seria explicado pelo aumento da fração haste na massa seca total .
Com o uso das doses de nitrogênio que permitiram as máximas produções (Tabela 2A) as produções estimadas de massa seca foliar foram superiores a 71, 69, 73, 91 e $90 \%$ aos valores produzidos de massa seca de hastes (Tabela 2B) entre as $5^{\text {a }}$ e $9^{\text {a }}$ coletas experimentais. A partir da ocorrência de condições climáticas favoráveis ao desenvolvimento do capim Tanzânia, tem-se uma participação maior estimada de folhas dentro do material coletado no período de maior produção do capim.

A quarta coleta apresentou uma quantidade estimada de massa seca foliar (1315,8 $\left.\mathrm{kg} \mathrm{MS} \mathrm{ha}^{-1}\right)$ menor que a quantidade de hastes produzidas $\left(1.553,9 \mathrm{~kg} \mathrm{MS} \mathrm{ha}{ }^{-1}\right)$, em função da ocorrência do florescimento durante este período. $\mathrm{O}$ uso de doses altas de nitrogênio propicia estímulo a um florescimento mais uniforme e aumento na produção de sementes.

De modo geral, e se observando a Tabela $2 \mathrm{~A}$ e B, vê-se predominância de equações quadráticas para os efeitos do nitrogênio sobre a produção de massa seca foliar, e de equações lineares para estimativas de produção de massa seca de hastes; assim, o uso de dosagens de nitrogênio além daquela considerada ótima para a massa seca foliar, acima daqueles previstos nas Tabela 4, proporcionaria a participação de uma fração maior de material considerado haste (colmo, hastes, material senescido) na massa seca total, que poderia apresentar menor qualidade nutricional e bromatológica.

\section{Produção de massa seca total, foliar e de hastes, nas diferentes estações de coleta}

Os testes de médias para produção média de massa seca total, foliar e de haste entre as diferentes estações de coleta, isolados ou comparados dentro de cada dosagem de nitrogênio usada, estão presentes nas Tabelas 3 e 4.

De maneira geral, as estações de estudo de inverno, primavera e verão, mostram-se como seqüência natural de aumento nas produções de massa seca totais e foliares, quando considerado um ciclo anual de crescimento para o capim Tanzânia. Exceção a esta seqüência seria a produção de massa seca de hastes que apresentaria, durante a estação do inverno, a ocorrência do florescimento do capim Tanzânia (Tabelas 3 e 4).

$\mathrm{O}$ uso de dose de nitrogênio acima de $275 \mathrm{~kg} \mathrm{~N} \mathrm{ha}^{-1}$ ano (ou $31 \mathrm{~kg} \mathrm{~N} \mathrm{ha}^{-1}$ coleta $^{-1}$ ), considerando-se uma seqüência de produção de massa seca entre as estações de inverno e verão, proporciona acréscimos nas produções de massa seca total e foliar durante os períodos favoráveis ao crescimento do capim de Tanzânia, de aproximadamente de $35 \%$ nas produções entre o inverno e primavera, e $52 \%$ ( $275 \mathrm{~kg} \mathrm{~N} \mathrm{ha}^{-1}$ ano $^{-1}$ ) e $35 \%$ (756 e $2079 \mathrm{~kg} \mathrm{~N} \mathrm{ha}^{-1} \mathrm{ano}^{-1}$ ) entre um período variando entre a primavera e o verão (Tabela 4).

Tabela 3. Variação de produção de massa seca total, foliar e de haste em três estações climáticas, em pastagem de capim Tanzânia estabelecido num Argissolo, avaliados na Fazenda Areão, Piracicaba, SP

\begin{tabular}{cccc}
\hline \multirow{2}{*}{ Estação } & \multicolumn{3}{c}{ Massa Seca* $\left(\mathrm{kg} \mathrm{MS} \mathrm{ha}^{-1}\right.$ período $\left.^{-1}\right)$} \\
\cline { 2 - 4 } & Total & Foliar & Haste \\
\hline Verão & $2817,5 \mathrm{a}$ & $2466,9 \mathrm{a}$ & $358,9 \mathrm{~b}$ \\
Inverno & $1031,2 \mathrm{c}$ & $602,1 \mathrm{c}$ & $429,1 \mathrm{a}$ \\
Primavera & $1384,6 \mathrm{~b}$ & $1220,6 \mathrm{~b}$ & $164,8 \mathrm{c}$ \\
\hline DMS & 147,3 & 115,12 & 57,81 \\
\hline Médias seguidas por letras distintas na mesma coluna diferem estatisticamente a $\mathrm{p}<0,05$
\end{tabular}


Tabela 4. Variação de produção de massa seca total, foliar e de haste em três estações climáticas, dentro das diferentes dosagens de nitrogênio usadas, em pastagem de capim Tanzânia estabelecido num Argissolo, avaliados na Fazenda Areão, Piracicaba, SP

\begin{tabular}{|c|c|c|c|}
\hline \multirow{2}{*}{$\begin{array}{c}\text { Dose } \mathrm{N} \\
\left(\mathrm{kg} \mathrm{ha}^{-1} \text { ano }^{-1}\right)\end{array}$} & \multicolumn{3}{|c|}{ Estação ${ }^{1}$} \\
\hline & Verão & Inverno & Primavera \\
\hline \multicolumn{4}{|l|}{ A. Total } \\
\hline 0 & $2097,5 a$ & $637,1 b$ & $453,6 \mathrm{~b}$ \\
\hline 100 & $2288,3 \mathrm{a}$ & $781,1 \mathrm{~b}$ & $695,9 \mathrm{~b}$ \\
\hline 275 & $2479,7 \mathrm{a}$ & 895,7 b & $1181,5 \mathrm{~b}$ \\
\hline 756 & $3110,7 \mathrm{a}$ & $1350,0 \mathrm{c}$ & $2116,5 \mathrm{~b}$ \\
\hline 2079 & $4111,8 \mathrm{a}$ & $1492,1 \mathrm{c}$ & $2475,6 \mathrm{~b}$ \\
\hline \multicolumn{4}{|l|}{ B. Foliar } \\
\hline 0 & $1884,9 \mathrm{a}$ & $406,4 \mathrm{~b}$ & $415,6 \mathrm{~b}$ \\
\hline 100 & $2057,5 \mathrm{a}$ & $478,1 \mathrm{~b}$ & $612,7 \mathrm{~b}$ \\
\hline 275 & $2270,2 \mathrm{a}$ & $563,0 \mathrm{c}$ & $1082,9 \mathrm{~b}$ \\
\hline 756 & $2780,3 \mathrm{a}$ & $830,3 \mathrm{c}$ & 1926,6 b \\
\hline 2079 & 3341,7 a & $732,9 \mathrm{c}$ & 2065,2 b \\
\hline \multicolumn{4}{|l|}{ C. Haste } \\
\hline (2) & $217,9 \mathrm{a}$ & 230,8 a & $41,7 \mathrm{~b}$ \\
\hline 100 & $234,4 \mathrm{ab}$ & $303,0 \mathrm{a}$ & $83,2 \mathrm{~b}$ \\
\hline 275 & $219,3 \mathrm{a}$ & 332,7 a & $98,6 \mathrm{~b}$ \\
\hline 756 & $387,1 \mathrm{ab}$ & 519,7 a & $189,9 \mathrm{~b}$ \\
\hline 2079 & $735,7 \mathrm{a}$ & $759,2 \mathrm{a}$ & $410,4 \mathrm{~b}$ \\
\hline
\end{tabular}

* Médias seguidas por letras distintas na mesma linha diferem estatisticamente a $p<0,05$ ${ }^{1} \mathrm{~kg} \mathrm{MS} \mathrm{ha-1}$ estação $\mathrm{O}^{-1}$

Considerando-se as estações climáticas estudadas, observa-se, com o aumento das doses de nitrogênio utilizadas, um aumento crescente nas produções de massa seca (total e foliar) determinadas (Tabela 4).

\section{Produção dos totais de massa seca durante o ano agrícola 2000/2001}

O quadro de análise de variância e as equações de regressão dos efeitos significativos para a massa seca total, foliar e de haste determinadas dos totais de produções obtidas durante todo o ciclo de pastejo estudado, são mostrados nas Tabelas 5 e 6.

Tabela 5. Equações de regressão para diferentes lâminas de irrigação e dose de nitrogênio, para a massa seca total, foliar e de haste dentro de um ciclo agrícola de pastejo, em uma pastagem de capim Tanzânia estabelecido num Argissolo, avaliados na Fazenda Areão, Piracicaba, SP

\begin{tabular}{|c|c|c|c|c|}
\hline $\mathrm{MS}^{1}$ & Equação & $\mathrm{R}^{2}$ & $\mathrm{MPMS}^{2}$ & $\begin{array}{l}\text { Lâmina } \\
\text { ou Dose } \\
\text { MPMS }^{3}\end{array}$ \\
\hline \multicolumn{5}{|c|}{ A. Lâmina } \\
\hline Total & $16.772,79-15,32 X$ & $0.75^{*}$ & $16.772,79$ & 0,00 \\
\hline Folha & NS & - & - & - \\
\hline Haste & NS & - & - & - \\
\hline \multicolumn{5}{|c|}{ B. Nitrogênio } \\
\hline Total & $\begin{array}{c}9.545,35+16,98 X- \\
0,0048 X^{2}\end{array}$ & $0,99^{* *}$ & $24.562,75$ & $1.768,75$ \\
\hline Folha & $\begin{array}{c}8.125,12+14,91 \mathrm{X}- \\
0,0047 \mathrm{X}^{2}\end{array}$ & $0,99^{* *}$ & $19.950,02$ & $1.586,17$ \\
\hline Haste & $1.442,55+1,95 X$ & $0,99^{* *}$ & $5.496,60$ & $2.079,00$ \\
\hline
\end{tabular}

Tabela 6. Equações de regressão para variação de dose de nitrogênio dentro de cada lâmina de irrigação usada, para a massa seca total, foliar e de haste, dentro de um ciclo agrícola de pastejo, em pastagem de capim Tanzânia estabelecido num Argissolo na Fazenda Areão, Piracicaba, SP

\begin{tabular}{|c|c|c|c|c|}
\hline Lâmina $^{1}$ & Equação & $\mathrm{R}^{2}$ & $\mathrm{MPMS}^{2}$ & $\begin{array}{l}\text { Dose N para } \\
\text { MPMS }^{3}\end{array}$ \\
\hline \multicolumn{5}{|c|}{ A. Massa seca total } \\
\hline 0 & $\begin{array}{c}11.912,87+12,32 \mathrm{X}- \\
0,00305 \mathrm{X}^{2}\end{array}$ & $0.99^{*}$ & $24.354,05$ & $2.019,67$ \\
\hline 30 & $\begin{array}{c}10.473,03+16,72 \mathrm{X}- \\
0,00548 \mathrm{X}^{2}\end{array}$ & $0,71^{* *}$ & $23.226,61$ & $1.525,55$ \\
\hline 70 & $\begin{array}{c}9.910,13+17,19 \mathrm{X}- \\
0,00446 \mathrm{X}^{2}\end{array}$ & $0,95^{* *}$ & $26.473,81$ & $1.927,13$ \\
\hline 100 & $\begin{array}{c}8.347,97+18.95 X- \\
0,00446 X^{2}\end{array}$ & $0,94^{* *}$ & $24.379,33$ & $1.691,96$ \\
\hline 150 & $\begin{array}{c}7.082,71+19,73 \mathrm{X}- \\
0,00560 \mathrm{X}^{2}\end{array}$ & $0,99^{* *}$ & $24.460,91$ & $1.761,61$ \\
\hline
\end{tabular}

B. Massa seca foliar

\begin{tabular}{|c|c|c|c|}
\hline $\begin{array}{c}9.746,39+11,35 \mathrm{X}- \\
0,0036 \mathrm{X}^{2}\end{array}$ & $0,99^{* *}$ & $18.692,40$ & $1.576,38$ \\
\hline $\begin{array}{c}8.793,51+13,89 X- \\
0,0046 X^{2}\end{array}$ & $0,73^{*}$ & $19.278,95$ & $1.509,78$ \\
\hline $\begin{array}{c}8.657,36+14,74 X- \\
0,0043 X^{2}\end{array}$ & $0,93^{* *}$ & $21.289,10$ & $1.713,95$ \\
\hline $\begin{array}{c}7.064,65+16,68 X- \\
0,0052 X^{2}\end{array}$ & $0,93^{* *}$ & $20.440,73$ & $1.603,85$ \\
\hline $\begin{array}{c}6.363,69+17,84 X- \\
0,0057 X^{2}\end{array}$ & $0,99^{* *}$ & $20.322,70$ & $1.564,91$ \\
\hline
\end{tabular}

C. Massa seca haste

$\begin{array}{cc}0 & \text { NS } \\ 30 & \text { NS } \\ 70 & \text { NS } \\ 100 & \text { NS } \\ 150 & \text { NS }\end{array}$

@ $\mathrm{p}<0,10 ; * \mathrm{p}<0,05 ; * * \mathrm{p}<0,01 ; * * * \mathrm{p}<0,001 ;$ NS - Não significativo

$\%$ da capacidade de campo

${ }^{2}$ MPMS - Máxima produção de massa seca $\left(\mathrm{kg} \mathrm{MS} \mathrm{ha}^{-1}\right.$ ano $\left.^{-1}\right)$

${ }^{3} \mathrm{~kg} \mathrm{~N} \mathrm{ha}^{-1}$ ano $^{-1}$

Quando considerado somente o estudo do efeito do uso das diferentes lâminas de irrigação na produção de massa seca total, observou-se efeito negativo do uso de água na produção de massa seca (Tabela 5) causado, possivelmente, por fatores físicos intrínsecos ao solo.

Com o não efeito da lâmina de irrigação, as equações ajustadas (Tabela 5) para uso de nitrogênio, poderiam ser consideradas como equações gerais para produções anuais de massa seca total, foliar e de hastes.

Assim, as produções estimadas pela Tabela 5 foram de $9.545,11.195,13.866,19.639$ e $24.100 \mathrm{~kg} \mathrm{MS} \mathrm{ha}^{-1}$ ano $^{-1}$ para massa seca total, e de 8.125, 9.569, 11.869, 16710 e $18.808 \mathrm{~kg} \mathrm{MS}$ $\mathrm{ha}^{-1}$ ano $^{-1}$ para massa seca foliar, quando utilizados $0,100,275$, 756 e $2079 \mathrm{~kg} \mathrm{~N} \mathrm{ha}^{-1} \mathrm{ano}^{-1}$, respectivamente .

Com o uso da dose de nitrogênio determinada para MPMS (Tabela 5) e colocando-a como limite máximo de nitrogênio para a adubação do capim Tanzânia neste experimento, constatou-se que este nutriente proporcionou aumentos de produção em relação às parcelas não adubadas, na ordem aproximada de 15,32 , 106 e $167 \%$ para massa seca total e foliar, em relação as doses 100, 275, 756 e $1.769 \mathrm{~kg} \mathrm{MS} \mathrm{ha}^{-1} \mathrm{ano}^{-1}$.

Os percentuais de incremento nas produções proporcionadas por cada uma dessas doses de nitrogênio na massa seca 
total, foram de $15,19,29$ e $20 \%$ quando usados doses de 100 , 275,756 e $1.769 \mathrm{~kg} \mathrm{MS} \mathrm{ha}^{-1} \mathrm{ano}^{-1}$, indicando que o uso de doses de nitrogênio superiores a $756 \mathrm{~kg} \mathrm{MS} \mathrm{ha-1} \mathrm{ano}^{-1}$ não mais proporcionaram efeitos positivos sobre a produção de massa seca em planta de capim Tanzânia.

Os valores de máxima produção de massa seca (MPMS) presentes na Tabela 6, estudando-se o efeito das diferentes doses de nitrogênio, apresentaram-se com semelhança de valores de produção de massa seca total e foliar, quando considerada cada lâmina de irrigação utilizada .

O uso da máxima dose de nitrogênio indicada na Tabela 6, indicou uma produção de massa seca total máxima de 24.562,75 kg de MS ha-1 ano $^{-1}$ para capim Tanzânia.

Comparando trabalhos semelhantes a este quanto à altura de corte e ao uso do nitrogênio, as respostas obtidas neste experimento (13.490 e $16.214 \mathrm{~kg}$ de MS ha-1 324 dias $^{-1}$, com 250 e $450 \mathrm{~kg} \mathrm{~N} \mathrm{ha}^{-1}$ ano $^{-1}$ ) foram inferiores às obtidas por Rosseto (2000) em capim Tanzânia, com aplicação de $250 \mathrm{~kg}$ de $\mathrm{N} \mathrm{ha}^{-1}$ $\operatorname{ano}^{-1}\left(20.806 \mathrm{~kg} \mathrm{de} \mathrm{MS} \mathrm{ha}^{-1} 214\right.$ dias $\left.^{-1}\right)$, e por Lugão (2001) em um Panicum maximum.(acesso BRA-006998) sob pastejo rotacionado, com a aplicação de $450 \mathrm{~kg} \mathrm{~N} \mathrm{ha}^{-1}$ ano $^{-1}(31.019 \mathrm{~kg}$ de MS ha-1 200 dias $^{-1}$ ). Considerando-se que os dois experimentos foram implantados em um solo classificado como Latossolo Vermelho para Rosseto (2000) e Vermelho-Amarelo para Lugão (2001), os quais apresentam características físicas diferentes do Argissolo usado neste experimento. Características de textura (argilosa e muito argilosa) e de porosidade (predominância de microporos), podem ter constituído um fator físico limitante a eficiência de uso das diferentes lâminas de irrigações para a obtenção de uma maior produtividade do capim Tanzânia neste trabalho de pesquisa.

\section{CONCLUSÕES}

1. Uso de doses de nitrogênio acima daquela considerada ótima para a produção de massa seca foliar (MDMS), proporciona aumento na fração de haste (colmo, hastes, material senecido) e na massa seca total.

2. As estações de inverno, primavera e verão mostram-se como a seqüência natural de aumento nas produções de massas seca total e foliar, quando considerados os ciclos anuais de crescimento para o capim Tanzânia.

3. Considerando-se a soma de todas as produções de massa seca total, observou-se efeito negativo do uso de água na produção, quando do aumento das lâminas de irrigação, onde, quando do uso de nitrogênio, produções foram estimadas em $9.545,11.195,13.866,19.639$ e $24.100 \mathrm{~kg} \mathrm{MS} \mathrm{ha}^{-1}$ ano $^{-1}$ para massa seca total, e de 8.125, 9.569, 11.869, 16710 e $18.808 \mathrm{~kg} \mathrm{MS}$ ha $^{-1}$ ano $^{-1}$ para massa seca foliar, quando utilizados $0,100,275$, 756 e $2079 \mathrm{~kg} \mathrm{~N} \mathrm{ha}^{-1} \mathrm{ano}^{-1}$, respectivamente .

4. O uso de doses de nitrogênio superiores a $756 \mathrm{~kg} \mathrm{~N} \mathrm{ha}^{-1}$ ano ${ }^{-1}$ não proporcionou efeitos crescentes sobre a produção de massa seca, sendo que os percentuais de incrementos nas produções proporcionadas pelo uso de nitrogênio até a máxima produção de massa seca total e foliar, mostraram ser de 15, 19, 29 e $20 \%$, quando usados as doses de 100, 275, 756 e 1.769 $\mathrm{kg} \mathrm{N} \mathrm{ha-1} \mathrm{ano}^{-1}$.

\section{LITERATURA CITADA}

Ararat, E.; Tafur, H. Efectos de la interaccion riego-fertilizacion sobre la produccion de forraje en tres pastos de corte. Acta Agronomica, Palmira, v.40, n.1/2, p.158-161, 1990.

Corsi, M. Estacionalidade de produções de forragens. Pirassununga, 1978, 18p.

Dias, P.F; Rocha, G.P.; Oliveira, A.I.G.; Pinto, J.C.; Rocha Filho, R.R.; Souto, S.M. Produtividade e qualidade de gramíneas forrageiras tropicais sob adubação nitrogenada no final do período das águas. Pesquisa Agropecuária Brasileira, Brasilia v.33, n.7, p.1191-1197, 1998.

Garcia, J.A.R. Efeito de diferentes lâminas d'água sobre a cultura da aveia irrigada por inundação temporária. Lavras: UFLA, 1993. 71p. Dissertação Mestrado

Jarvis, S.C.; Scholefield, D.; Pain, B. Nitrogen cycling in grazing systems . In: Bacon, P.E. Nitrogen fertilization in the environment. New York: Marcel Dekker, 1995. cap.10, p.381-419.

Ladeira, N.P.; Sykes, D.J.; Daker, A.; Gomide, J.A. Estudos sobre produção e irrigação dos capins pangola, sempre verde e gordura, durante o ano de 1965. Revista Ceres, Viçosa, v.12, n.74, p.105-116, 1966.

Lugão, S.M.B. Produção de forragem e desempenho animal em pastagens de Panicum maximum (Jacq.) (acesso BRA006998) adubadas com nitrogênio na região do Noroeste do estado do Paraná. Jaboticabal: UNESP, 2001. 151p. Tese Doutorado

Nascimento Junior, D.; Queiroz, D.S.; Santos, M.V.F. Degradação das pastagens e critérios para avaliação. In: Simpósio sobre Manejo da Pastagem, 11, Anais... Piracicaba: FEALQ, 1994. p.129-156.

Pinheiro, V.D. Viabilidade econômica da irrigação de pastagem de capim Tanzânia em diferentes regiões do Brasil. Piracicaba: ESALQ/USP, 2002. 85p. Dissertação Mestrado

Rosseto, F.A.de A. Desempenho agronômico de pastagens de capim elefante cv. Guaçu (Pennisetum purpureum Schum,) e de capim Tanzânia (Panicum maximum Jacq. ) em sistema de produção de leite. Piracicaba: ESALQ/USP, 2000. 174p. Dissertação Mestrado

Vallentine, J.F. Grazing management. San Diego: Academic Press, 1990. 533p.

Vicente-Chandler, J. Intensive grassland management in Puerto Rico. Revista da Sociedade Brasileira de Zootecnia, Viçosa, v.2, n.2, p.173-215, 1973.

Vicente-Chandler, J.; Silva, S.; Figarella, J. Effect of frequency of application on response of Guinea grass to nitrogen fertilization. The Journal of Agriculture of the University of Puerto Rico, Rio Piedras, v.46, n.4, p.343-349, 1962. 